\title{
Bimanual Motor Skill in Recruitment of Forest Harvest Machine Operators
}

\author{
Millana Pagnussat, Theresa Hauge, Eduardo da Silva Lopes, \\ Rosa Maria Martins de Almeida, Alana Naldony
}

\begin{abstract}
The great complexity of the operation of wood harvesting machines and unpredictable differences of performance between operators must be reflected in the industry recruitment techniques. This work aimed to carry out an evaluation of the bimanual motor skill in candidates for the position of harvester operators using a virtual reality simulator to generate information that can contribute to and improve the selection process. The work was developed at the Forest Operators Training Center (CENFOR), at the State University of the Center-West, in Irati, PR. A sample of 12 individuals was studied and distributed into three levels of performance. The motor ability of the individuals was evaluated through the variables: "run time", "fall direction ", and »cutting height ", assessed at different points during a 4-hour practice - 0.5; $1.0 ; 1.5 ; 2.0 ; 3.0$ and 4.0 hours - practice in a virtual harvester simulator. The data were analyzed by variance and means, as well as compared to a Tukey test at the 5\% level of significance. The individuals had a significant difference in the variables »run time" and »cutting height", and could be accurately used to predict bimanual motor skill/performance. There was a significant gain in the performance of the operators up to 1.5 hours after the beginning of the skill test, and all those who demonstrated greater and lesser ability in the first half hour of the test maintained this behavior until the end of the training period. The virtual reality simulator can be used as a tool to assess bimanual motor skills during the selection of harvester operators.
\end{abstract}

Keywords: forestry, training, individual characteristics, motor skills

\section{Introduction}

In the forest-based sector, wood harvesting and wood transportation has significant economic importance, accounting for $50 \%$ to $70 \%$ of the timber final cost, $30 \%$ to $50 \%$ in pulp and paper production, and $50 \%$ to $80 \%$ in wood products (Lews 2008, Machado 2014).

Currently, these operations have been carried out by means of increasingly sophisticated, automated, high cost, machines with high productivity (Lopes 2001, Machado 2014). In this sense, the high production costs of wood harvesting are directly affected by the hourly productivity of machine operators. Productivity depends on the characteristics of the site, species, machines, and machine operators (Lopes et al. 2011). Kärhä et al. (2004), Ovaskainen (2005), and Pürfurst (2010) reported that experienced operator productivity varied by about $50 \%$ among operators. During the training period, this variation can reach $120 \%$. So this significant variation becomes an important issue to be studied.

According to Pagnussat and Lopes (2017), and Pürfurst (2010), the greatest challenge for the implementation of new technologies in the area of wood harvesting is the shortage of qualified professionals to operate and maintain the highly complex and technical machines. Therefore, in order to improve the efficiency and productivity of forest operations, it is crucial to select operators with good training, motor skills, as well as their personality combined with their individual capacities (Harstela 2004, Volodina et al. 2015).

In South Africa, Wenhold et al. (2019) found that the results of cutting with harvester were $60 \%$ lower than shown by the population mean test. These analyses were performed in thinning operations and include processing of the wood, besides all others field and forest variables. Yet the authors have ultimately 
found that the operators reached the end of their learning curves after an average of six to nine months, and increased their productivity performances by $104 \%$ to $218 \%$ since they started using the simulator training.

The mechanized harvesting of wood, being a very repetitive activity, is an operation very influenced by the experience and skill of the operator (Pürfurst 2010, Lopes et al. 2011). The ability of an individual is related to the capacity to fulfill a specific task with a certain level of skill and expertise (Ferreira 2009). This skill and expertise can be acquired over time, and prior work has confirmed that skill acquisition occurs in adult individuals in a variety of contexts, such as work, leisure, or rehabilitation (Anguera et al. 2011, Heuer and Hegele 2015).

Although motor ability increases through practice (Corrêa et al. 2010), the rate of acquisition is highly variable among individuals. Therefore, neuroscientists, who study motor skills, seek to understand these neurocognitive processes related to this motor skill learning given the motor cortical plasticity that involves differential neural systems and cognitive processes (Kim et al. 2015, Seidler and Carson 2017).

Brain plasticity is the adaptive capacity of the nervous system in response to experience, such as adaptation to repeated stimuli and conditions. However, this development depends on internal processes that vary between individuals, which are affected by factors such as the individual's age, body part to be developed, physical capacity or even motivation and attention (for a review, see Wulf and Lewthwaite 2016). It may also be said that a person's individual motor skills respond is responsible for performing an action in a constant way over time different from the others (Schmidt and Wrisberg 2008).

The wood harvesting activity is a bimanual task, requiring the use of both cerebral hemispheres as well as fast and efficient communication between the hemispheres. Synchronous and precise coordination of the activity of the two hands is important. This ability also impacts both daily routine tasks and many manual skills (such as playing a musical instrument) (Seitz et al. 2004, Jeeves et al. 1988).

The complexity between-hand temporal constraints of discrete coordination may rely more on interhemispheric control (Stancak et al. 2003). This work suggests that we may find specific differences in continuous bimanual activity, which relies on the corpus callosum for inter-limb temporal coordination from different people, ages or conditions (Kennerley et al. 2002).

In this context, it is hypothesized that people have significant differences in motor ability affecting performance in training forest machine operations. The goal of this research was to determine whether there are significant differences in the motor skill of forest machine operators, in the initial phase of the simulator,
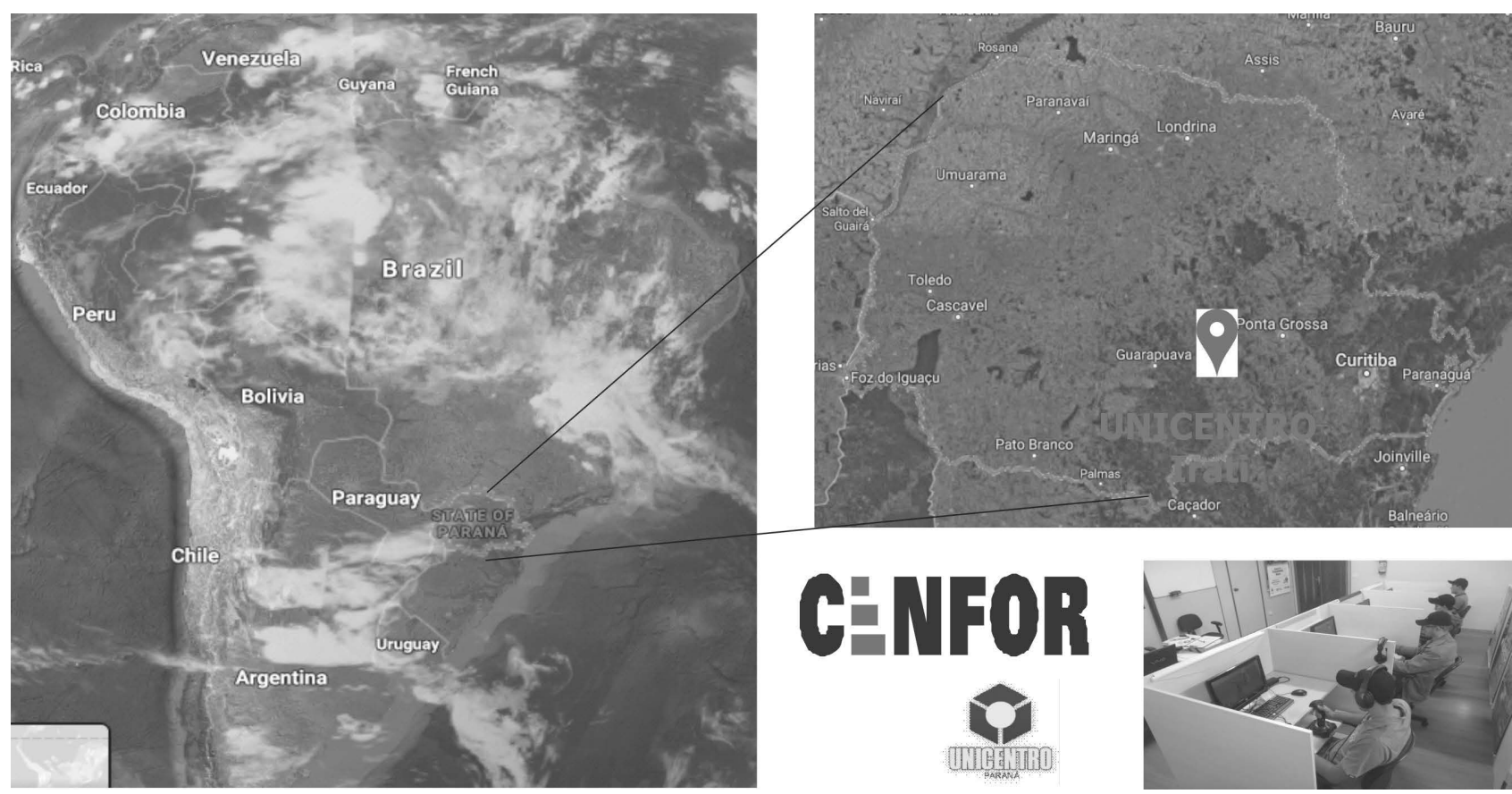

Fig. 1 Studied area (Source: Google maps) 
and if this lack of ability is consistent during their learning curve. This information can contribute to additional methodology used in operator identification and evaluation.

\section{Material and Methods}

The research was carried out at the Training Center for Forest Operators (CENFOR), at the Midwest State University (UNICENTRO) in Parana - Brazil (Fig. 1). The study was carried out on a random sample of 12 individuals (4 female, 8 male) ranging in age from 18 to 24 , with no history of brain lesions and with no experience as machine operators.

\subsection{Equipment Used}

Virtual reality simulators were used, using the Sim$\log$ Simulation Launcher harvester simulation program, mounted on computers and equipped with joysticks (Fig. 2).
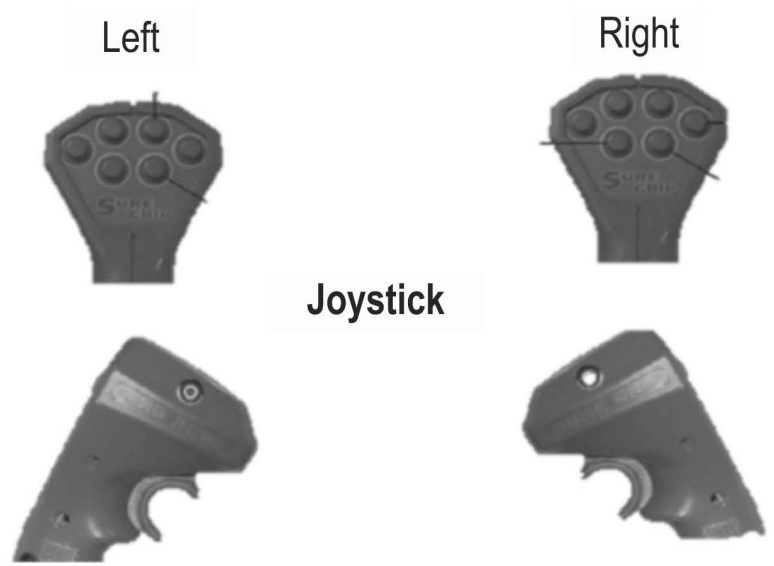

Fig. 2 Virtual reality simulator on computers equipped with joystick
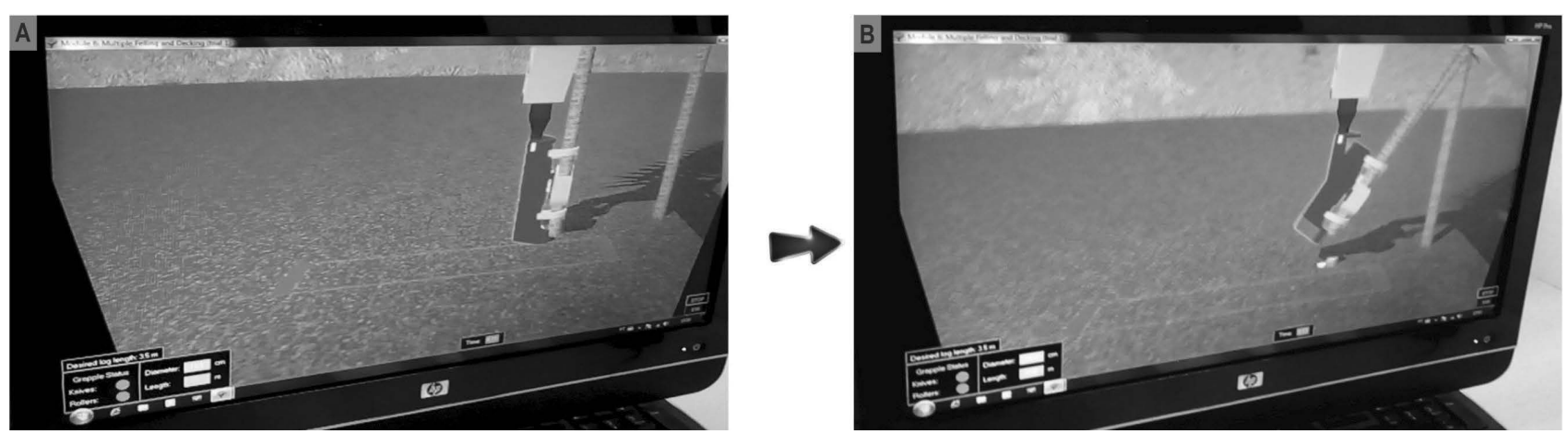

\subsection{Data Collection}

Data were collected in 5 consecutive days totaling 40 hours of training. In total, the simulator was in use for data collection for 3 weeks - one for each group tested in three distinct weeks. Survey participants received basic information about the forest cutting operation and basic instructions on the functions and commands of the virtual simulator; they also took part in the simulation of the forest cutting operation for an initial period of 15 minutes to adapt to commands and simulations.

The training simulation program consisted of $7 \mathrm{op}-$ erational modules: module 1 (joysticks commands), for 2 hours; module 2 (control of movements), for 6 hours; module 3 (single-tree cutting), for 8 hours; module 4 (single-tree cutting and logging), for 6 hours; module 5 (simple processing and stacking) for 6 hours; module 6 (multiple stacking and logging) for 4 hours; and module 7 (processing), for 8 hours (Lopes et al. 2018).

The simulation module 2 was designed for motor skill assessment in the virtual reality simulator. In

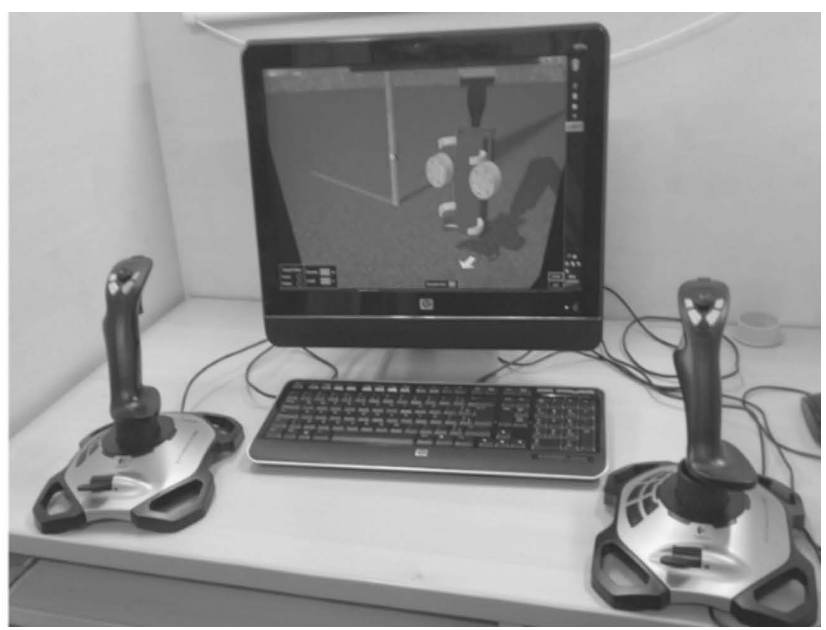

Fig. 3 Virtual reality simulator module 2 ( $A$ - Cut, B - Felling) 
Table 1 Description of variables evaluated in the execution of module 2 of the harvester simulator

\begin{tabular}{|l|l|}
\hline \multicolumn{1}{|c|}{ Variable } & \\
\hline Run time, $\mathrm{s}$ & Time required to execute the cutting cycle of a tree, in seconds \\
\hline Fall direction, degrees & Error of orientation of falling of the tree in degrees, in relation to the pre-determined marking by the simulator \\
\hline Cutting height, $\mathrm{cm}$ & Relationship between the positioning height of the cutting set in relation to the pre-determined marking by the simulator \\
\hline
\end{tabular}

Table 2 Description of profile classification

\begin{tabular}{|c|c|c|l|}
\hline Class & Run time, s & Person in group & \\
\hline 1 & $11-40$ & 3 & They performed the operation in less time, demonstrating a good understanding of movement and great motor skill \\
\hline 2 & $41-70$ & 5 & They performed the operation in an average time, demonstrating understanding of movement and motor skill \\
\hline 3 & $71-100$ & 4 & They performed the operation with difficulty, over a long period of time, demonstrating difficulty of movement with less motor skill \\
\hline
\end{tabular}

module 2 , the task was to execute the cutting operation, that is, to fell and process a single tree per simulation cycle (Fig. 3).

The data were collected at intervals of $0.5 ; 1.0 ; 1.5$; 2.0; 3.0 and 4.0 hours, evaluating the following variables: »run time«, »fall direction « and »cutting height«, the operation being described by the evaluated variables as presented in Table 1.

After the training period, we analyzed the participant's performance and they were classified according to their initial results of the »run time« variable in the first evaluation. Following the Gaussian distribution, three subgroups were obtained to perform the motor skill tests (Table 2).

Finally, a final evaluation after 40 hours of training was carried out, using the percentage of all seven modules covered during the training, in order to evaluate whether the performance of the operators in the first hours remained constant throughout the training.

For this, the productivity was evaluated in module 4 , where the operator is presented to a scenario more similar to a real field situation, involving the cutting, processing, and stacking of the wood in a pre-set location. An average productivity of the last two hours of operation of the participants was calculated.

\subsection{Statistical Analysis}

The statistical analysis consisted of a factorial design, with motor skills of individuals in the three classes of operators as treatments, being evaluated in six test periods of time. The variances were analyzed by the Bartlett test and the means compared by the Tukey test post hoc at the $95 \%$ level of significance.
The comparison of the means of productivity of the individuals in the final modules of training and of the use at the end of 40 hours of training was also performed to analyze if the classes maintained the initial ranking. A Tukey test was used post hoc at the $95 \%$ level of significance.

\section{Results}

The performance of the individuals studied based on three variables is shown in Table 3. When analyzing the skills of the operators among operators' classes, the operators in class 1 had better performance scores in all variables studied, however on »run time « and "cutting height «, there were significant differences at the $5 \%$ probability level. It is important to note that the shorter the »run time«, the greater the operator's agility in performing the action.

In the variables "run time« and »cutting height«, the operator classes showed significant differences between them ( $p$ value $<0.0005)$. However, the variables »cutting height « and »fall direction « did not present significant differences among them across the simulator training sessions.

Figs. 4 and 5 show the individuals' motor skills studied by the variables »cutting height « and »runtime « in the three performance classes during the execution time of the simulations.

The individuals presented a difference of ability in the three performance classes evaluated, showing improvement in the operation, but did not present statistically significant gain during the first four hours of operation in relation to »cutting height«. 
Table 3 Performance scores obtained by individuals performing the skill test in relation to variables evaluated in virtual simulator

\begin{tabular}{|c|c|c|c|c|c|c|c|c|c|c|c|c|c|}
\hline \multicolumn{14}{|c|}{ Variable »Run Time», S } \\
\hline \multirow{2}{*}{\multicolumn{2}{|c|}{ Class }} & \multicolumn{12}{|c|}{ Skill test duration time, $\mathrm{h}$} \\
\hline & & \multicolumn{2}{|c|}{0.5} & \multicolumn{2}{|c|}{1} & \multicolumn{2}{|c|}{1.5} & \multicolumn{2}{|c|}{2} & \multicolumn{2}{|c|}{3} & \multicolumn{2}{|c|}{4} \\
\hline \multirow{2}{*}{1} & $A$ & 38 & \multirow{2}{*}{$\mathrm{Ca}$} & 28 & \multirow{2}{*}{ Cab } & 22 & \multirow{2}{*}{$\mathrm{Cbc}$} & 23 & \multirow{2}{*}{$\mathrm{Cbc}$} & 21 & \multirow{2}{*}{ Ccd } & 19 & \multirow{2}{*}{$\mathrm{Cd}$} \\
\hline & SD & 4.38 & & 2.33 & & 2.36 & & 2.62 & & 3.13 & & 3.57 & \\
\hline \multirow{2}{*}{2} & A & 55 & $\mathrm{Ba}$ & 49 & $\mathrm{Bab}$ & 42 & $\mathrm{Bbc}$ & 43 & $\mathrm{Bbc}$ & 34 & Bcd & 31 & $\mathrm{Bd}$ \\
\hline & SD & 3.42 & - & 5.45 & - & 4.73 & - & 4.95 & - & 5.41 & - & 3.57 & \\
\hline \multirow{2}{*}{3} & $A$ & 80 & $\mathrm{Aa}$ & 70 & Aab & 65 & $A b c$ & 65 & $A b c$ & 50 & Acd & 39 & $\mathrm{Ad}$ \\
\hline & SD & 4.47 & - & 5.73 & - & 3.73 & - & 4.22 & - & 5.12 & - & 3.95 & \\
\hline \multicolumn{14}{|c|}{ Variable »Fall direction», degrees } \\
\hline \multirow{2}{*}{\multicolumn{2}{|c|}{ Class }} & \multicolumn{12}{|c|}{ Skill test duration time, $\mathrm{h}$} \\
\hline & & \multicolumn{2}{|c|}{0.5} & \multicolumn{2}{|c|}{1} & \multicolumn{2}{|c|}{2.5} & \multicolumn{2}{|c|}{2} & \multicolumn{2}{|c|}{3} & \multicolumn{2}{|c|}{4} \\
\hline \multirow{2}{*}{1} & A & 12.7 & Aa & 9.7 & $\mathrm{Aa}$ & 9.7 & $\mathrm{Aa}$ & 8.5 & $\mathrm{Aa}$ & 9.5 & $\mathrm{Aa}$ & 9.7 & $\mathrm{Aa}$ \\
\hline & SD & 2.41 & - & 3.12 & - & 2.73 & - & 3.91 & - & 2.92 & - & 3.81 & - \\
\hline \multirow{2}{*}{2} & $A$ & 14.8 & $\mathrm{Aa}$ & 12.6 & $\mathrm{Aa}$ & 11.2 & $\mathrm{Aa}$ & 12.3 & $\mathrm{Aa}$ & 11.7 & $\mathrm{Aa}$ & 12.5 & $\mathrm{Aa}$ \\
\hline & SD & 3.15 & - & 4.35 & - & 3.84 & - & 4.15 & - & 2.38 & - & 3.23 & - \\
\hline 2 & $A$ & 18.0 & $\mathrm{Aa}$ & 9.5 & $\mathrm{Aa}$ & 8.8 & $\mathrm{Aa}$ & 10.1 & $\mathrm{Aa}$ & 8.9 & $\mathrm{Aa}$ & 9.5 & $\mathrm{Aa}$ \\
\hline$\checkmark$ & SD & 3.56 & - & 2.42 & - & 4.54 & - & 3.52 & - & 3.16 & - & 3.57 & - \\
\hline & & & & & & Variah & tting $h$ & II, $\mathrm{cm}$ & & & & & \\
\hline & & & & & & & $\|$ test & on tim & & & & & \\
\hline & & & & & & & & & & & & & \\
\hline 1 & $A$ & 7.5 & $\mathrm{Ba}$ & 5.8 & $\mathrm{Ba}$ & 5.1 & $\mathrm{Ba}$ & 6.4 & $\mathrm{Ba}$ & 5.4 & $\mathrm{Ba}$ & 5.8 & $\mathrm{Ba}$ \\
\hline 1 & SD & 2.21 & - & 2.48 & - & 2.29 & - & 3.6 & - & 2.46 & - & 3.91 & - \\
\hline$?$ & A & 10.6 & $\mathrm{ABa}$ & 8.8 & Aba & 7.0 & Aba & 5.8 & $\mathrm{ABa}$ & 6.0 & Aba & 7.5 & $\mathrm{ABa}$ \\
\hline & SD & 3.56 & - & 2.44 & - & 2.90 & - & 3.54 & - & 2.6 & - & 3.41 & - \\
\hline & $A$ & 13.4 & $\mathrm{Aa}$ & 11.6 & $\mathrm{Aa}$ & 8.3 & $\mathrm{Aa}$ & 10.8 & $\mathrm{Aa}$ & 10.5 & $\mathrm{Aa}$ & 8.2 & $\mathrm{Aa}$ \\
\hline & SD & 2.66 & - & 3.65 & - & 3.73 & - & 3.18 & - & 2.45 & - & 3.69 & - \\
\hline
\end{tabular}

* Averages subscripted by the same letter do not differ statistically from each other, ${ }^{*} \mathrm{SD}=$ Standard Deviation, ${ }^{*} \mathrm{~A}=$ Average value

Regarding the variable "run time of the cut off cycle, it can be noted that individuals in the three performance classes maintained the same ranking over the period evaluated; namely, between 30 minutes and 4 hours of evaluation, individuals maintained their positions in each class.

There was a significant difference in skill gain over the 4 hours of execution. Therefore, a very sig- nificant gain was observed in the first four hours of operation.

Table 4 presents the percentage of total performance of the three classes of operators at the end of the training process. As can be seen, the individuals studied in the profile classes maintained a mean performance difference, with the same rating of the first 4 hours of operation, during all 40 hours of training. 


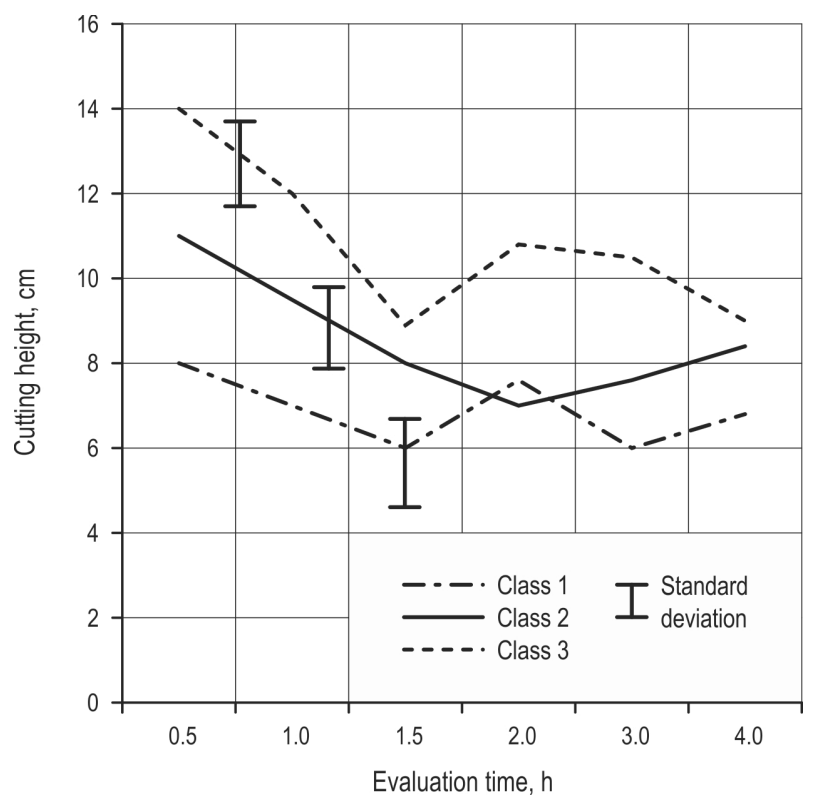

Fig. 4 Performance of individuals of different profiles in the first hours of operation in relation to the variable »cutting height»

Table 4 Variation of performance of individuals in profile classes during training

\begin{tabular}{|c|c|c|}
\hline Class & $\begin{array}{c}\text { Final performance of operators } \\
\text { in virtual simulator, } \%\end{array}$ & $\begin{array}{c}\text { Standard } \\
\text { deviation }\end{array}$ \\
\hline 1 & $97 \mathrm{a}$ & 6.3 \\
\hline 2 & $88 \mathrm{ab}$ & 6.5 \\
\hline 3 & $78 \mathrm{~b}$ & 6.9 \\
\hline
\end{tabular}

* Means followed by the same letter do not differ statistically from each other by the Tukey test at $5 \%$ of error probability

Fig. 6 shows the productivity results of the last simulator modules, where module 6 refers to the felling, processing and stacking of several trees and module 7 only refers to the processing of trees.

The average performance in the three classes of operators presented differences, but there was no significant difference in the variables evaluated between the first two performance classes at the end of the training. However, the first two classes presented a significant difference in relation to the third class of operators.

\section{Discussion}

The significant differences between the variables »run time« and »cutting height«, and the non-significant differences among the variables »cutting height"

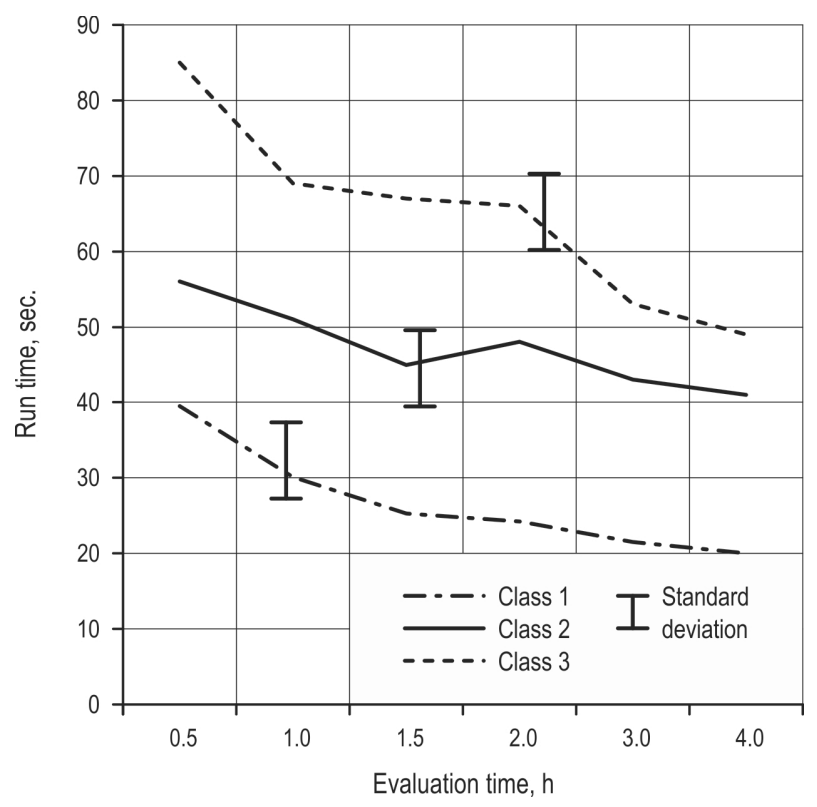

Fig. 5 Operation performance in the first hours of the variable »run time»

and »fall direction « may have occurred because in the first moments of the operation, the individual is instructed to perform the task correctly, focusing on quality regardless of time. In this way, individuals required more patience than skill for the quality of the cut. According to the data, very little variation was

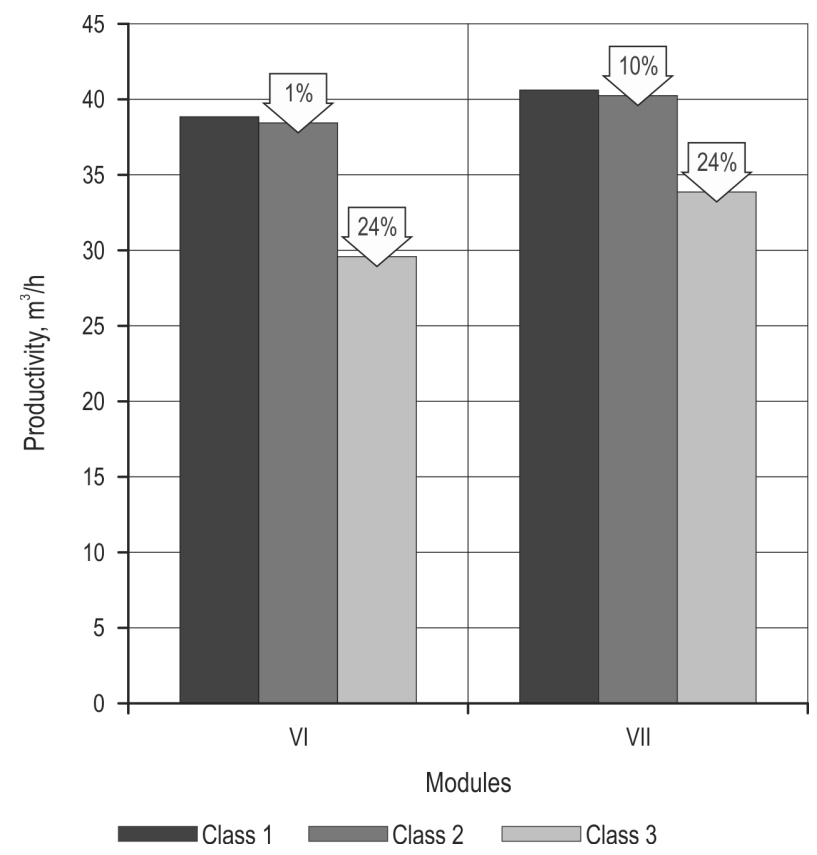

Fig. 6 Performance of individuals in profile classes at the end of training in virtual reality simulator 
observed along the training period that each individual took to achieve the end of skill gain period. The "run time « (s) tended to stabilize in the first four hours of operation of the first module evaluated.

The significant variation in the "cutting height" and "run time « variables can be attributed to the fact that both variables are more complex. In the case of "run time", greater agility is required of the individual to develop operational skills more quickly. However, for the "cutting height « variable, more specific characteristics are needed for a future operator, such as greater attention to detail, depth and spatial perception.

The individuals presented a difference of ability in the three performance classes evaluated, showing improvement in the operation, but did not present statistically significant gain during the first four hours of operation in relation to »cutting height «. This result can be attributed to the fact that operators are initially instructed to carry out the operation carefully, focusing on quality independent of time.

Therefore, it can be observed that individuals presented significant differences in preliminary motor skill assessment. As Lopes and Pagnussat (2017) argued, not all people have the same ability to perform forest machine operations, reinforcing the fact that individuals are different and do not have the same capabilities in a given function.

Regarding the variable "run time« of the cut off cycle, it can also be noted that individuals in the three performance classes maintained the same ranking over the period evaluated. Therefore, it is possible to affirm that the test to evaluate the motor skill of individuals to the position of forest machine operator can be applied within a duration of 30 minutes, allowing evaluation of candidates during the selection process.

In this sense, these results can be explained by the difference between the individuals. According to Chiavenato (2010), people differ both in the ability to learn a task and in the level of its accomplishment after learning. Individuals present large individual differences, both physical (height, weight, sex, physical fitness, strength, visual and auditory acuity, resistance to fatigue, etc.) and psychological differences (temperament, character, aptitude, intelligence, etc.) that lead to different behavior, perception, and performance in a given motor context.

The difference of ability in the evaluation of the three performance classes in relation to »cutting height « can be attributed to the fact that operators are initially instructed to carry out the operation carefully, focusing on quality independent of time.
The variable »cutting height « has a qualitative evaluation, so although a slight improvement in performance can be observed as a skill gain, it was not statistically significant, and those who found it easier to perform the operation demonstrated the same quality, but with less time.

However, it was possible to evaluate significant difference in initial ability between the three classes of operators. In this way the operators did not present significant gain but they presented performance differences between classes of operators, demonstrating the skill variation among beginners in the operation of the machine simulator.

As some individuals need more time than the initial hours of training for the movement improvement, Lopes et al. (2008) state that »cutting height « is considered an important variable in the evaluation of operator performance, since it requires the operator's coordination in the execution of cuts in different positions, besides being a limitation on the quality of the operation and identification of mistakes made.

Regarding the significant difference in skill gain over the 4 hours of execution, in studying the performance of operators in similar conditions, Lopes et al. (2008) emphasized the significant improvement of $52 \%$ in the performance of operators in the variable "run time«, and therefore a very significant gain was observed in the first four hours of operation.

In addition, the "run time « is a significant variable at the beginning of the training, being fundamental in the productivity of the operation and showing great importance in the selection process.

The »run time « of the operation requires agility and motor skill. Studying the tacit knowledge of forest operators in Finland, Ranta at al. (2004) observed that a skilled forest operator is able to perform the movements smoothly, using the kinetic energy developed during the execution of the operation with synchronized movements, a situation that decreases the »run time « and increases productivity.

Table 4 presents the percentage of total performance of the three classes of operators. There was little difference in productivity between individuals in classes 1 and 2, but this difference remained in relation to the individuals in class 3 . The differences between classes 1 and 2 and 3 are considerable at a larger scale, since in large production scales, a productive difference of $24 \%$ becomes representative.

The significant difference at the end of the training, therefore, shows that the result achieved in the first half hour of operation may be indicative of the potential of the individual's mechanical ability. 
Thus, the classification determined by the variables »run time« and »cutting height « in the first half-hour of the skill test were maintained throughout the training, demonstrating potential use of the virtual reality simulator in the determination of individuals with greater motor ability to operate forest machines.

\section{Conclusion}

A significant difference was found in performance and motor skills between the different operators, and this research indicates a necessity to carry out a more rigorous selection process in the future that allows finding the appropriate individual for the position of operator.

The variables »run time « and »cutting height « were appropriate as a parameter to assess the motor skill of candidates for forestry machine operators, and have shown the potential to be used in the selection process.

The motor skill test can be performed with a 30-minute virtual reality simulator, because although the individuals obtained operating gains in this period, no inversions were observed in the overall classification before this period.

The virtual reality simulator has proved to be an efficient tool for determining motor skills and can be used in the selection process of forest harvesting machine operators.

\section{Acknowledgments}

This study was financed in part by the Coordenação de Aperfeiçoamento de Pessoal de Nível Superior - Brasil (CAPES) - Finance Code 001.

\section{References}

Beek, P.J., Peper, C.E., Daffertshofer, A., 2002: Modeling Rhythmic Interlimb Coordination: Beyond the Haken-Kelso-Bunz Model. Brain and Cognition 48(1): 149-165. https:// doi.org/10.1006/brcg.2001.1310

Bressler, S.L., Kelso, J.A., 2001: Cortical coordination dynamics and cognition. Trends in Cognitive Sciences 5(1): 26-36. https://doi.org/10.1016/S1364-6613(00)01564-3

Corrêa, U.C., Ugrinowitsch, H., Benda, R.N., Tani, G., 2010: Effects of practice schedule on the adaptive process of motor learning. Rev Port Cien Desp 10(1): 158-171.

Harstela, P., 2004: The competence of the forest-machine operator and tacit knowledge. In: The proceedings of Development Project in Forest Machine Based Training. Finnish Forest Reseach Institute/ University of Joensuu, Finland, 1-25.

Kärhä, K., Rönkkö, E., Gumse, S., 2004: Productivity and Cutting Costs of Thinning Harvesters. International Journal of Forest Engineering 15(2): 43-56. https://doi.org/10.1080/1494 2119.2004.10702496
Kelso, J.A.S., 1995: Dynamic Patterns: The Self-Organization of Brain and Behavior. MIT Press, Cambridge, MA, 1-334.

Kennerley, S.W., Diedrichsen, J., Hazeltine, E., Semjen, A., Ivry, R.B., 2002: Callosotomy patients exhibit temporal uncoupling during continuous bimanual movements. Nature Neuroscience 5(4): 376-381. https://doi.org/ 10.1038/nn822

Lopes, E.S., 2001: Aplicação do programa SNAP III (Scheduling and Network Analysis Program) no planejamento da colheita e do transporte florestal. Viçosa, MG: UFV, 2001. 150 f. (Tese de Doutorado em Ciência Florestal), Universidade Federal de Viçosa, Viçosa, 1-150.

Lopes, E.S., Cruziniani, E., Araujo, A.J., Silva, P.C., 2008: Evaluation of harvester operator training using virtual reality simulators. Revista Árvore 32(2): 291-298. http://dx.doi. org/10.1590/S0100-67622008000200012

Lopes, E.S., Pagnussat, M.B., 2017: Effect of the behavioral profile on operator performance in timber harvesting. International Journal of Forest Engineering 28(3): 134-139. https:// doi.org/10.1080/14942119.2017.1328847

Lopes, E.S., Vosniak, J., Fiedler, N.C., Inoue, M.T., 2011: Analysis of Human Factors and Working Conditions in Forest Deployment Operations. Floresta 41(4): 707-714.

Machado, C.C., 2014: Colheita Florestal. Universidade Federal de Viçosa, 1-468.

Marteniuk, R.G., MacKenzie, C.L., Baba, D.M., 1984: Bimanual movement control: Information processing and interaction effects. The Quarterly Journal of Experimental Psychology 36(2): 335-365. https://doi.org/10.1080/14640748408402163

Ovaskainen, H., 2005: Comparison of harvester work in forest and simulator environments. Silva Fennica 39(1): 89-101. https://doi.org/10.14214/sf.398

Pagnussat, M.B., 2015: Behavioral Profile in Harvester Forest Tractor Operator Selection and Performance Process. Dissertação (Mestrado em Ciências Florestais) - Universidade Estadual do Centro-Oeste, Irati.

Pagnussat, M.B., Lopes, E.S., 2017: The behavioral profile of harvester operators. Revista Árvore 41(2): e410210. http:// dx.doi.org/10.1590/1806-90882017000200010

Pagnussat, M.B., Lopes, E.S., Silva, P.C., Diniz, C.C.C., Watzlawick, L.F., 2014: Operators Performance of Different Ages in Training with Forwarder Virtual Simulator. Enciclopédia Biosfera 18(10): 3842-3852.

Parise, D.J., 2005: Influence of special personal requirements on the performance of high-performance harvesting machine operators. Master Thesis in Forest Engineering, Federal University of Paraná, Curitiba, 1-148.

Ranta, P., Laamanen, V., Pohjolainen, S., Väätäinen, K., 2004: Making a Harvester Operators' Tacit knowledge Explicit. Tampere University of Technology, Digital Media Institute. Hypermedia Laboratory.

Schmidt, R.A., Wrisberg, C.A., 2008: Motor learning and performance: A situation-based learning approach, $4^{\text {th }}$ ed. Champaign, IL, US: Human Kinetics, 1-395.

Schöner, G., Kelso, J.A.S., 1988: Dynamic Pattern Generation in Behavioural and Neural System. Science 239: 1513-1520. https://doi.org/10.1126/science.3281253 
Sherwood, D.E., 1994: Hand preference, practice order, and spatial assimilations in rapid bimanual movement. Journal of motor behavior 26(2): 123-134. https://doi.org/10.1080/00222 895.1994.9941667

Spijkers, W., Heuer, H., 1995: Structural Constraints on the Performance of Symmetrical Bimanual Movements with Different Amplitudes. The Quarterly Journal of Experimental Psychology 48(3): 716-740. https://doi. org/10.1080/14640749508401412

Stancak, A., Cohen, E.R., Seidler, R.D., Duong, T., Kim, S., 2003: The size of corpus callosum correlates with functional activation of medial motor cortical areas in bimanual and unimanual movements. Cerebral Cortex 13(5): 475-485. https://doi.org/10.1093/cercor/13.5.475

Swinnen, S.P., Young, D.E., Walter, C.B., Serrien, D.J., 1991: Control of asymmetrical bimanual movements. Experimental Brain Research 85(1): 163-173. https://doi.org/10.1007/ BF00229998
Swinnen, S.P., Walter, C.B., Lee, T.D., Serrien, D.J., 1993: Acquiring Bimanual Skills: Contrasting Forms of Information Feedback for Interlimb Decoupling. Journal of Experimental Psychology Learning Memory and Cognition 19(6): 13281344. https://doi.org/10.1037//0278-7393.19.6.1328

Turvey, M.T., 1990: Coordination. American Psychologist 45(8): 938-953. http://dx.doi.org/10.1037/0003-066X.45.8.938

Volodina, A., Nagy, G., Köller, O., 2015: Success in the first phase of the vocational career: The role of cognitive and scholastic abilities, personality factors, and vocational interests. Journal of Vocational Behavior 91: 11-22. https://doi. org/10.1016/j.jvb.2015.08.009

Wenhold, R., Ackerman, P., Ackerman, S.A., Gagliardi, K., 2019: Skills development of mechanized softwood saw timber cut-to-length harvester operators on the Highveld of South Africa. International Journal of Forest Engineering, https:// doi.org/10.1080/14942119.2019.1578561

(C) 2019 by the authors. Submitted for possible open access publication under the terms and conditions of the Creative Commons Attribution (CC BY) license (http://creativecommons.org/licenses/by/4.0/).

Received: March 8, 2019

Accepted: September 9, 2019
Authors' addresses:

Prof. Millana Pagnussat, $\mathrm{PhD}$ * e-mail: millanap@gmail.com Assoc. Prof. Eduardo da Silva Lopes, PhD e-mail: eslopes@irati.unicentro.br Allana Naldony e-mail: naldonyalana@gmail.com Universidade Estadual do Centro-oeste UNICENTRO

Department of Forest Engineering PR 153, Km 7, s/n - Riozinho 84500000 Irati, Paraná BRAZIL

Theresa Hauge, PhD student e-mail: theresa.hauge@ufl.edu University of Florida Department of Applied Physiology \& Kinesiology 32611, Gainesville, Florida USA

Assoc. Prof. Rosa M. M. de Almeida, PHD e-mail: rosa_almeida@yahoo.com Universidade Federal do Rio Grande do Sul (UFRGS) Department of Psychology Rua Ramiro Barcelos, 2600 Room 216 90035-001, Porto Alegre, Rio Grande do Sul BRAZIL

* Corresponding author 